\title{
Morphological and molecular characterization of powdery mildew on watermelon plants in São Paulo state
}

\author{
Evelynne Urzêdo Leão ${ }^{* *}$ C, Norberto Silva, Kelly Cristina Gonçales Rocha², \\ Marcelo Agenor Pavan ${ }^{3}$ (D), Gentil Cavalheiro Adorian ${ }^{4}$, Renate Krause-Sakate ${ }^{3}$ (D) \\ 'State University of Tocantins, Brasil. \\ ${ }^{2}$ Grandes Lagos Union of Colleges \\ ${ }^{3}$ Paulista State University \\ ${ }^{4}$ Catholic University Center of Tocantins \\ *Corresponding author, e-mail: evelynnegpi@gmail.com
}

\begin{abstract}
Powdery mildew is one of the most commom foliar diseases of cultivated and wild cucurbits worldwide. Six different fungal species have been reported to be associated with powdery mildew of cucurbits, such as Podosphaera xanthii and Golovinomyces cichoracearum. The aim of the study was to identify the causal agent of the disease in watermelon plants (Citrullus lanatus) cultivated in greenhouses of the State of São Paulo. DNA total was extracted using Chelex method and the ITS region was amplified via standard PCR reaction using the specific primers PMITS1 and PMITS2. A fragment of 700pb was amplified and the sequence showed $99 \%$ of identity with $P$. xanthii (accession number JQ728480). Morphological observation showed that the conidia were ellipsoidal-ovoid, had fibrosin bodies and a bifurcated germinative tube in the lateral position. These characteristics and the molecular analyses confirmed $P$. xanthi as the etiological agent of powdery mildew in watermelon plants in São Paulo State.
\end{abstract}

Keywords: Citrullus lanatus, Podosphaera xanthii, molecular identification, PCR

In Brazil, watermelon (Citrullus lanatus) is one of the most important cucurbit crops. In 2013, the average production of watermelon was 2 milion ton, with a total cultivated area of 90,000 ha placing Brazil as the fourth largest producer of watermelon in the world (FAO, 2014). Powdery mildew is an endemic disease present in many crop species worldwide, especially cucurbits. The pathogen occur in almost all places where melons (Cucumis melo), cucumbers (Cucumis sativus), pumpkins (Cucurbita sp.) and watermelon are cultivated. It is more prominent in places with high temperatures and low humidity during the growing season, or under protected crop growing (Naruzawa et al., 2011).

Six different fungal species have been reported to be associated with powdery mildew in cucurbits. Podosphaera xanthii (=Sphaerotheca fuliginea) and Golovinomyces cichoracearum (=Erysiphe cichoracearum) are the most common and of economically importance (Aguiar et al., 2012). These two fungal species have often been misidentified (Ramos et al., 2011), due to similarities in their anamorphic characteristics. These organisms differ in virulence against cucurbit species and in their sensitivity to fungicides.
P. xanthii is more frequent in Brazil, being adapted to regions of tropical and subtropical climates, whereas G. cichoracearum occurs in dry weather and more frequently in temperate regions (Naruzawa et al., 2011).

Powdery mildew causes significant yield loss in watermelon as well as decreases fruit quality, through mycelial coverage of the leaves, leaf necrosis, and premature death of the plant (Ferreira et al., 2015; Soares et al., 2016). In recent studies regarding the powdery mildew in melon and cucumber in conventional or protected cultivation published in Brazil, only P. xanthii is cited as the etiological agent and represents the pathogen in the perfect form (Aguiar et al., 2012). Thus, the aim of the study was to identify the etiological agent of the disease in watermelon plants cultivated in greenhouses of São Paulo State.

Fresh leaf samples were collected from watermelon and were used for observation of characteristics of anamorphic stage. Fresh hyphae and conidia were stripped off from the leaf surfaces with platinum loop, and then mounted on a microscope slide, and examined in water under light microscope. The size of 20 conidia of each 10 samples, collected 
randomly, was measured. The following morphological characteristics were examined: shape and dimensions of conidia, presence or absence of fibrosin bodies $13 \%$ of $\mathrm{KOH})$, location and shape germ tubes.

For the molecular analysis, the DNA total of powdery mildew samples were extracted from mycelia by the Chelex method (Cunnington et al., 2003). A small amount $\left(<1 \mathrm{~mm}^{3}\right.$ ) of the fungus was scraped from the host plant and placed into $50 \mu \mathrm{L}$ of buffer (5\% Chelex 100 (Sigma-Aldrich) and $0.01 \%$ Triton X-100 (Sigma-Aldrich)). This was incubated at $56{ }^{\circ} \mathrm{C}$ for $2 \mathrm{~h}$ (vortexing briefly after $1 \mathrm{~h}$ ), vortexed, incubated in boiling water for $8 \mathrm{~min}$, vortexed and spun in a bench-top centrifuge at 20.000 rpm for $5 \mathrm{~min}$. The top $40 \mu \mathrm{L}$ was removed, added to $40 \mu \mathrm{L}$ isopropanol, mixed, left on ice for $10 \mathrm{~min}$ and centrifuged for $10 \mathrm{~min}$ at $20.000 \mathrm{rpm}$. The supernatant was then removed and the sample was dried and resuspended in $40 \mu \mathrm{L}$ of DEPC-treated water.

The PCR was performed in $25 \mu \mathrm{l}$ containing $3.0 \mu \mathrm{l}$ of DNA sample, $12.5 \mu$ of Master Mix buffer (PCR Master Mix, Promega, USA), $8.0 \mu \mathrm{l}$ of DEPC-treated water, 1.0 $\mu \mathrm{l}$ of $6 \%$ Tween 20 and $0.25 \mu \mathrm{l}$ of each primers PMITS I (5'-TCGGACTGGCC (T/C)AGGGAGA-3') and PMITS2 (5'-TCACTCGCCGTTACTGAGGT-3'), that was specifically designed for Erysiphales internal transcribed spacer (ITS) regions from 185 and $28 \mathrm{~S}$ sequences (Cunnington et al., 2003). PCR reaction was carried out in a thermal cycler with an initial heating step of $94^{\circ} \mathrm{C}$ for 10 minutes and 35 cycles of: denaturing $\left(94^{\circ} \mathrm{C} / 1\right.$ minute), primer annealing $\left(65^{\circ} \mathrm{C} / 1\right.$ minute) and extension $\left(72^{\circ} \mathrm{C} / 2\right.$ minutes $)$, followed by a final extension of $72^{\circ} \mathrm{C}$ for 10 minutes. The results were analyzed through electrophoresis in agarose gel (0.8\%) stained with Neotaq Brilliant Green Plus DNA Stain (Neobio, Brazil). PCR products were purified using Qiagen PCR purification kit (Qiagen, Inc. Valencia, CA, USA), according to the manufacturer's protocol and sent for direct sequencing.

The nucleotide sequences were analyzed by MEGA 5.0 and compared with nucleotide sequences in databases using BLAST. A phylogenetic tree was constructed with the Neighbour-Joining method with 2000 bootstrap replications using the software MEGA.

Results showed that the symptoms observed on the samples of watermelon leaves are typically associated with powdery mildew (Figure 1). All samples have the similar morphological characteristics from powdery mildew species (Figure 2). In this study the conidia presented the same reproduction patterns observed in previous research with this species (Aguiar et al., 2012), for example, they produced in chains, varying from ellipsoid to ovoid form, with $34.7 \pm 1.6 \times 25.9 \pm 7.2 \mu \mathrm{m}$ of conidia size. Observation of conidia in $3 \% \mathrm{KOH}$ indicated the presence of fibrosin bodies commonly found in the cucurbit powdery mildew genus Podosphaera.

The germination tubes ranged from apical to forked side. In our work we observed that the morphological characteristic of the fungus present in the watermelon crop corresponds to the telemorphic form, P. xanthii.

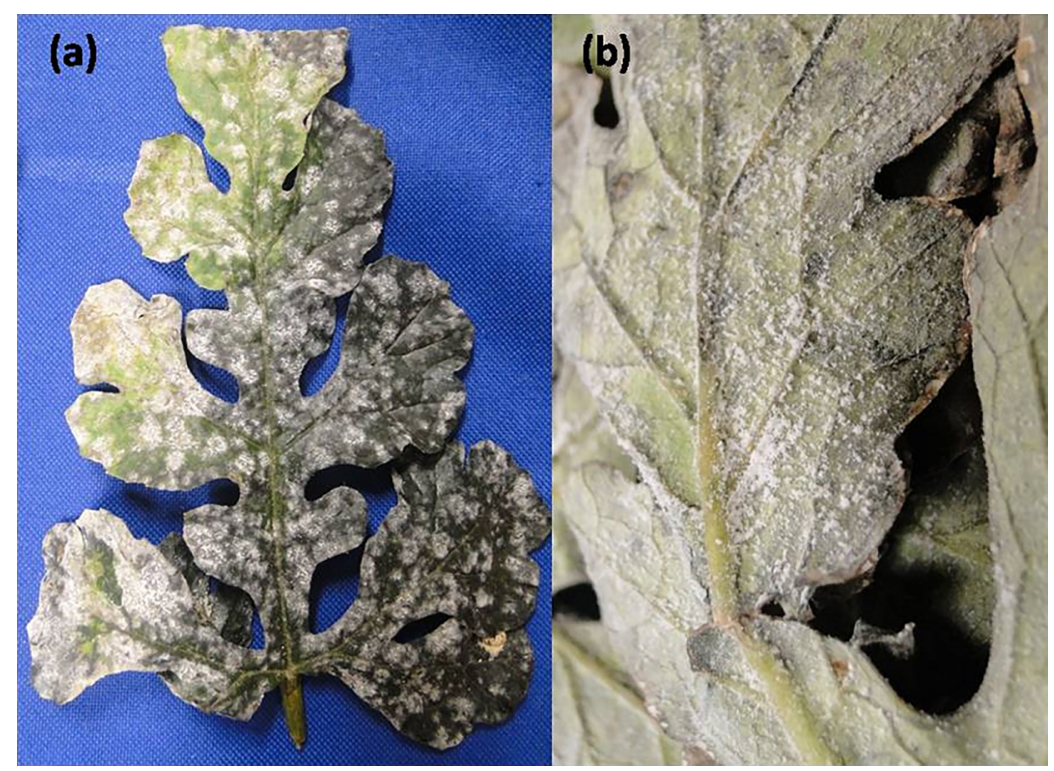

Figure 1. Symptoms of powdery mildew on watermelon leaf. Mycelium white on the adaxial (a) and abaxial (b) surface of the leaf. 
P. xanthii (=S. fuliginea) and G. cichoracearum are considered as the two important species of cucurbit powdery mildews around the world (Aguiar et al., 2012). However, P. xanthii it is usually misidentifying with P. fusca, because both species have similar morphological form. $P$. xanthii and $P$. fusca can be distinguished only by the morphology of sexual structures or through sequences of ITS region of the ribosomal DNA (Braun et al., 2001). In this way, the use of molecular tools is important to differentiate between these species, preventing further misidentification.

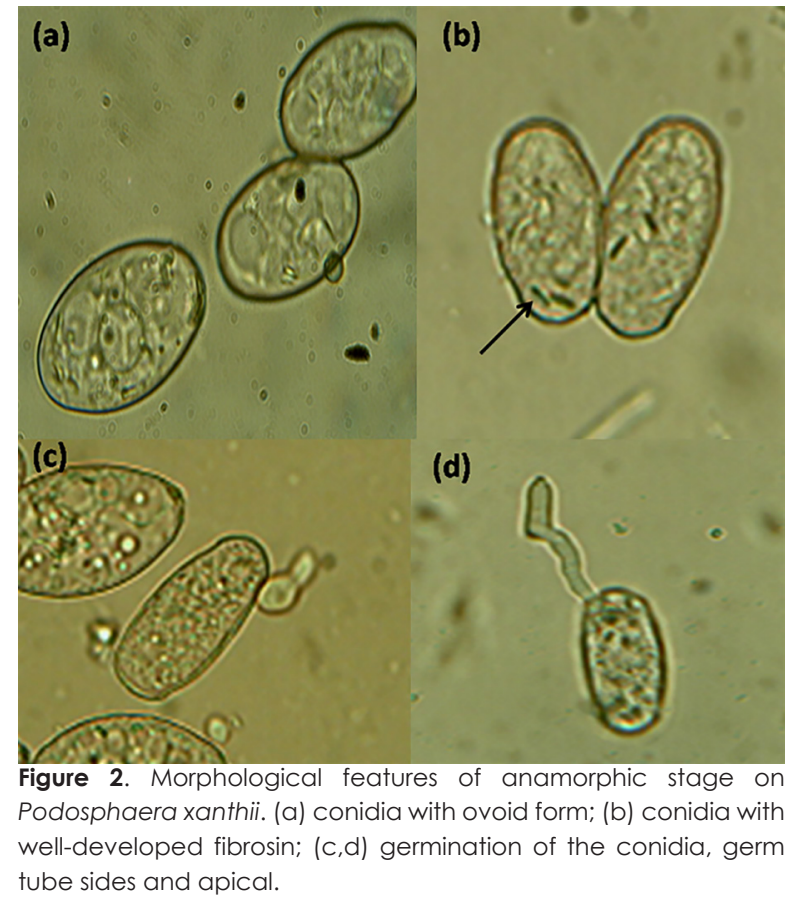

As a result, PCR product of 700bp was amplified from fungal DNA samples using the primers PMITS1 and PMITS2, specific for Erysiphales (Cunnington et al., 2003). All samples collected and sequencing showed $100 \%$ homology with the sequence of $P$. xanthii (JQ728480) deposited in GenBank. Similar results was found by Kousik et al. (2011), with $100 \%$ identity to the ITS sequences of $P$. xanthii in the GenBank database.

The phylogenetic analysis reveals that the investigated pathogen can be classified into the same cluster group of $P$. xanthii (Figure 3). The ribosomal DNA ITS region is useful for studying fungi at the species level (Porter \& Golding, 2011). According to Cunnington et al. (2003), this genomic region is used for phylogenetic studies in inter-specific level, and it applies particularly to members of the genus Podosphaera.

On the basis of morphological characteristics and ITS sequence, the analysis observed, the P. xanthii as the most strongly associated pathogen infecting watermelon crops.

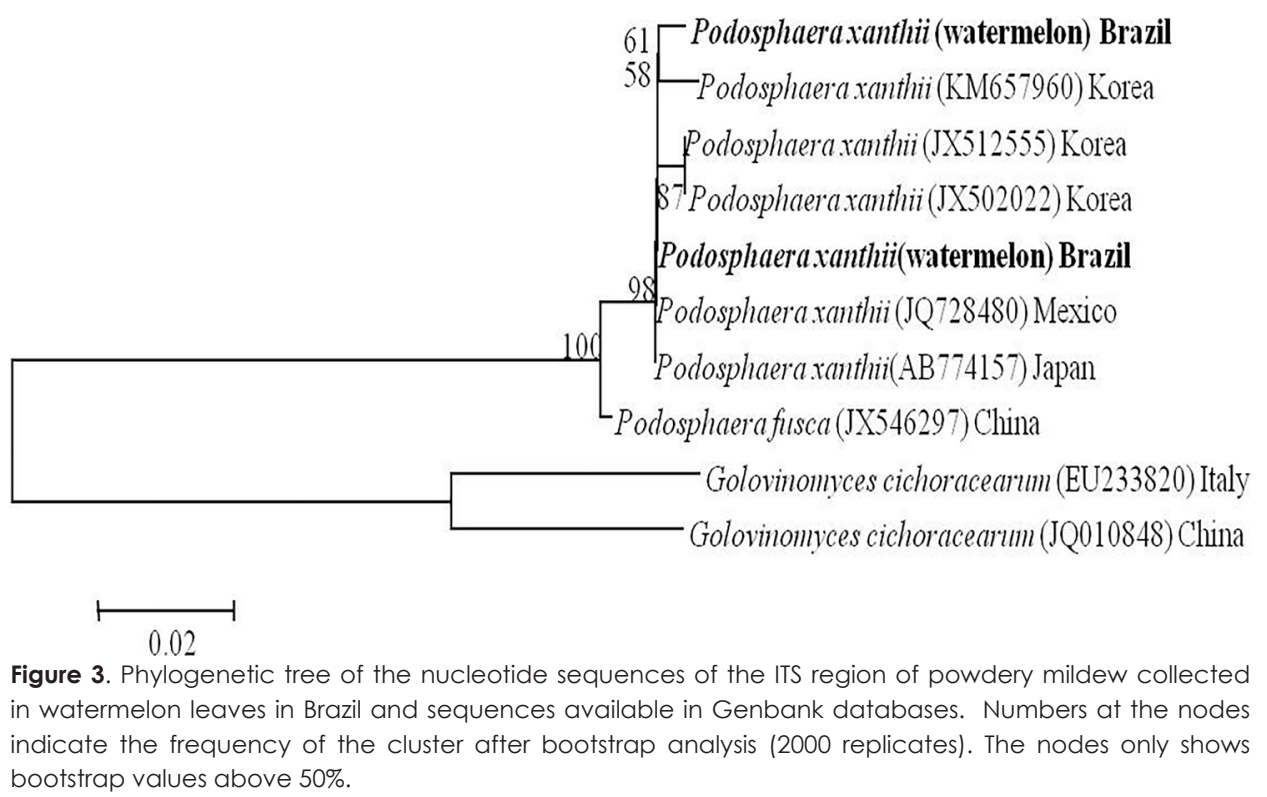




\section{References}

Aguiar, B.M., Vida, J.B., Tessmann, D.J., Oliveira, R.R., Aguiar, R.L., Alves, T.C.A. 2012. Fungal species that cause powdery mildew in greenhouse-grown cucumber and melon in Paraná State, Brazil. Acta Scientiarum Agronomy 34: $247-252$

Braun, U., Shishkoff, N., Takamatsu, S. 2001. Phylogeny of Podosphaera sect. Sphaerotheca subsect. Magnicellulatae (Sphaerotheca fuliginea auct. s.lat.) inferred from rDNA ITS sequences - a taxonomic interpretation. Schlechtendalia 7: 45-52.

Cunnington, J.H., Takamatsu, S., Lawrie, A.C., Pascoe, I.G. 2003. Molecular identification of anamorphic powdery mildews (Erysiphales). Australasian Plant Pathology 32: 421-428.

FAO. Food and Agriculture Organization of the United Nations. 2014. http://faostat.fao.org/site/339/default.asp <Access on 10 Mar. 2014>

Ferreira, R.R., Oliveira, G.K.C., Negreiros, A.M.P., Silva, F.G., Sales Júnior, R. 2015. Avaliação da eficácia de amistar top no controle do oídio do meloeiro Podosphaera xanthii. Agropecuária Científica no Semiárido 11: 127-130.

Kousik, C.S., Donahoo, R.S., Webster, C.G., Turechek, W.W., Adkins, S.T., Roberts, P.D. 2011. Outbreak of cucurbit powdery mildew on watermelon fruit caused by Podosphaera xanthii in Southwest Florida. Plant Disease 95: 1586.

Naruzawa, E.S., Vale, R.K.D., Silva, C.M., Camargo, L.E.A. 2011. Estudo da diversidade genética de Podosphaera xanthii através de marcadores AFLP e seqüências ITS. Summa Phytopathologica 37: 94-100.

Porter, T.M., Golding, G.B. 2011 . Are similarity-or phylogenybased methods more appropriate for classifying internal transcribed spacer (ITS) metagenomic amplicons? New Phytologyst 192: 775-782.

Ramos, C.B., Maruthachalam, K., McCreight, J.D., Estrada, R.S.G. 2011 . Podosphaera xanthii but not Golovinomyces cichoracearum infects Cucurbits in a Greenhouse at Salinas, California. Cucurbit Genetics Cooperative Report 33-34: 24-28.

Soares, M.G.O., Soares, J.A., Cezar, M.A., Cardoso, T.A.L., Lima, J.A.A. 2016. Ocorrência de patógenos em cultivos de melancia e abóbora no sertão da Paraíba. Revista Verde de Agroecologia e Desenvolvimento Sustentável 11:

Conflict of Interest Statement: The authors declare that the research was conducted in the absence of any commercial or financial relationships that could be construed as a potential conflict of interest.

All the contents of this journal, except where otherwise noted, is licensed under a Creative Commons Attribution License attribuition-type BY. 